JMTM 32,9

Received 17 December 2019 Revised 7 May 2020 15 July 2020

Accepted 20 July 2020

\section{Factors for metal additive manufacturing technology selection}

\author{
Vladimir C.M. Sobota and Geerten van de Kaa \\ Faculty of Technology, Policy and Management, Delft University of Technology, \\ Delft, The Netherlands \\ Toni Luomaranta and Miia Martinsuo \\ Department of Industrial Engineering and Management, Tampere University, \\ Tampere, Finland, and \\ J. Roland Ortt \\ Faculty of Technology, Policy and Management, Delft University of Technology, \\ Delft, The Netherlands
}

\begin{abstract}
Purpose - This paper addresses the most important factors for the selection of additive manufacturing (AM) technology as a method of production of metal parts. AM creates objects by adding material layer by layer based on 3D models. At present, interest in AM is high as it is hoped that AM contributes to the competitiveness of Western manufacturing industries.

Design/methodology/approach - A literature study is conducted to identify the factors that affect the selection of AM technology. Expert interviews and the best-worst method are used to prioritize these factors based on relative factor weights.

Findings - Technology, demand, environment and supply-related factors are categorized and further mapped to offer a holistic picture of AM technology selection. According to expert assessments, market demand was ranked highest, although market demand is currently lacking.

Research limitations/implications - The composition and size of the expert panel and the framing of some of the factors in light of previous literature cause validity limitations. Further research is encouraged to differentiate the selection factors for different AM implementation projects.

Originality/value - The paper presents a more complete framework of factors for innovation selection in general and the selection of AM technology specifically. This framework can serve as a basis for future studies on technology selection in the (additive) manufacturing sector and beyond. In addition to AM-specific factor weights, the paper explains why specific factors are important, reducing uncertainty for managers that have to choose between alternative manufacturing technologies.
\end{abstract}

Keywords Additive manufacturing, 3D printing, Metal additive manufacturing, Technology selection, Best-worst method, BWM

Paper type Research paper

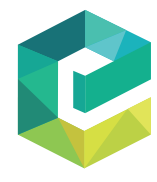

(c) Vladimir C.M. Sobota, Geerten van de Kaa, Toni Luomaranta, Miia Martinsuo and J. Roland Ortt. Published by Emerald Publishing Limited. This article is published under the Creative Commons Attribution (CCBY 4.0) licence. Anyone may reproduce, distribute, translate and create derivative works of this article (for both commercial and non-commercial purposes), subject to full attribution to the original publication and authors. The full terms of this licence may be seen at http://creativecommons. org/licences/by/4.0/legalcode

This paper was written as part of I AM RRI project ("Webs of Innovation Value Chains of Additive Manufacturing under Consideration of RRI") that received funding under the EC H2020 SWAFT 122017 programme (grant number 788361). The authors thank Marianne Hörlesberger and Brigitte Kriszt for helpful comments on earlier versions of this paper. 


\section{Introduction}

In early 2020, General Electric unveiled its new jet engine GE9X, which includes several additively manufactured metal parts (Kellner, 2020). The applications of additive manufacturing (AM), which creates objects by adding material layer by layer based on 3D models, are no longer limited to prototyping as it is also used for the production of functional parts (Atzeni and Salmi, 2012). And yet, news about General Electric using additively manufactured functional parts in its new jet engine still creates a stir in the AM community and beyond. Inspired by AM's unique capabilities, policymakers and the public have shown increased interest in AM. For instance, the European Commission sees AM as a promising technology with great economic potential.

Nevertheless, the diffusion of AM practical applications is lagging behind expectations, and additively manufactured components continue to be the exception rather than the norm. Currently, metal AM accounts only for a tiny fraction of the global manufacturing market, less than $0.1 \%$, to be precise, according to a market report by 3DHubs (2019, p. 8). Given these figures, it seems pressing to study the underlying factors that influence the selection of AM technology in the manufacturing technology market. These factors may help to explain why AM technology was selected as the method of production instead of several other possible alternatives and thereby help the AM sector move toward large-scale implementation.

Only sparse research focuses on factors for the selection of innovative AM technology (Yeh and Chen, 2018). While some studies explore challenges and drivers related to the implementation of AM technology (Dwivedi et al., 2017; Martinsuo and Luomaranta, 2018; Mellor et al., 2014), few studies focus on AM technology selection among alternative production methods or prioritize such factors. Some exceptions include studies conducted in Taiwan (Yeh and Chen, 2018), the USA and UK (Hasan et al., 2019; Schniederjans, 2017; Schniederjans and Yalcin, 2018) and India (Marak et al., 2019). Europe, as the second biggest AM market after the USA according to a 2019 AMFG report, has not yet been studied in this respect. By including literature related to technology dominance, technology diffusion, AM adoption, technology acceptance and business models, we offer a more encompassing framework for AM technology selection. The goal is to identify factors for the selection of AM technology as the method of production and to prioritize these factors using expert interviews. The information from the interviews is analyzed using the best-worst method (BWM). The main research question is: "What are the most important factors for the selection of AM technology in the European context according to experts?" We will focus on AM of metal parts rather than polymer, concrete or other materials.

The literature study results in a framework of 39 factors for innovation selection in general and the selection of metal AM technology specifically. Prioritizing these factors for the case of metal AM in Europe clearly shows that the demand for AM products in the market, relative technological performance and the business model behind AM are the most important. Interestingly, market demand ranks highest even though there is currently a lack thereof, as pointed out by interviewees. The prioritization of factors informs both theory and practice as it adds to the literature on the antecedents of AM selection and reduces uncertainty for managers that cannot address all factors simultaneously.

\section{Literature review}

\section{Overview on metal additive manufacturing}

AM utilizing metals is a relatively innovative manufacturing technology that currently comprises five mainstream self-standing technological solutions (Zhang et al., 2017): Powder Bed and Inkjet 3D Printing (3DP), Selective Laser Sintering (SLS), Direct Metal Laser Sintering (DMLS), Direct Metal Deposition (DMD) and Electron Beam AM (EBAM).

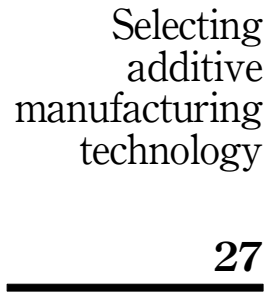

Selecting additive acturing 
JMTM 32,9
Each of these solutions has its own specialties, but for the purpose of this study (selection of AM technology), these applications are assessed under the umbrella term of metallic AM. Metallic AM can be combined with other manufacturing technologies to create more efficient and complex manufacturing possibilities (Gibson, 2017). Martinsuo and Luomaranta (2018) argue that metallic AM can best be viewed as a systemic innovation that requires complementary innovations in other manufacturing, business and supply chain processes as well as cooperation with other companies in the focal company's supply chain. Therefore, AM is introducing a new paradigm for manufacturing industries with the possibility to disrupt companies' contemporary business logics (Weller et al., 2015).

When producing end-useable parts or components, the following process chain is usually followed. AM always requires a suitable 3D model, the expertise of a product designer (functionality of the design) and an AM expert to optimize the design for production with AM (Luomaranta and Martinsuo, 2020). This differs from traditional subtractive manufacturing where a digital model is not always necessary. AM also requires specific machines and specific raw materials, usually powdered metals (Khajavi et al., 2014). Operating AM machines requires specific skill sets from the operating personnel (Murmura and Bravi, 2018). After manufacturing, objects need to be postprocessed (Khajavi et al., 2014) and quality checked before being assembled as a component into a product or before using the AM object as an end product. AM brings the following benefits: no specific tooling is needed, reducing production time and expense, small product batches are economically feasible, products can be custom-made and product designs can be changed quickly and easily, product designs can be more complex, less waste is generated and shorter and more agile supply chains with low inventory needs can be used (Holmström et al., 2010).

\section{Selecting and adopting additive manufacturing technology}

Previous research has studied factors for the selection and adoption of AM technology from various perspectives, including but not limited to metal AM. Table 1 groups such studies according to the factors that are discussed in these studies. Many papers study factors related to AM technology as a technological innovation. Frequently reoccurring are factors such as cost, material and energy consumption, as well as aspects of the design and manufacturing process. The group demand-related includes different factors studied from the perspective of actors that select AM technology. Often mentioned are experience with and knowledge of $\mathrm{AM}$, the size of the company that selects AM technology and the general demand for AM technology. Factors that influence AM selection at the aggregate level (and for several types of materials including metal, polymers, etc.) are summarized under environmental factors, including the availability of standards, geographical location and the influence of multinationals. Yet other papers study AM in the context of a supply chain, stressing the alignment and integration of efforts.

Although these studies establish more and less important factors based on their individual contexts, it is difficult to compare the importance of factors across studies precisely because of this richness in contexts and foci. A much smaller group of studies addresses this problem by compiling lists of factors and prioritizing these. Table 2 presents an overview of the six studies that have studied the relative importance of various factors across several AM technologies.

Although these studies draw on different theoretical frameworks and empirical contexts, all find that, in a broader sense, relative (technological) advantage is an important factor, though with differences in detailedness. However, the studies also disagree on several factors: trialability, social influences, facilitating conditions and compatibility are mentioned among both the most and least important factors. Table 2 clearly shows that more than half of the studies draw on the USA as a research context. 


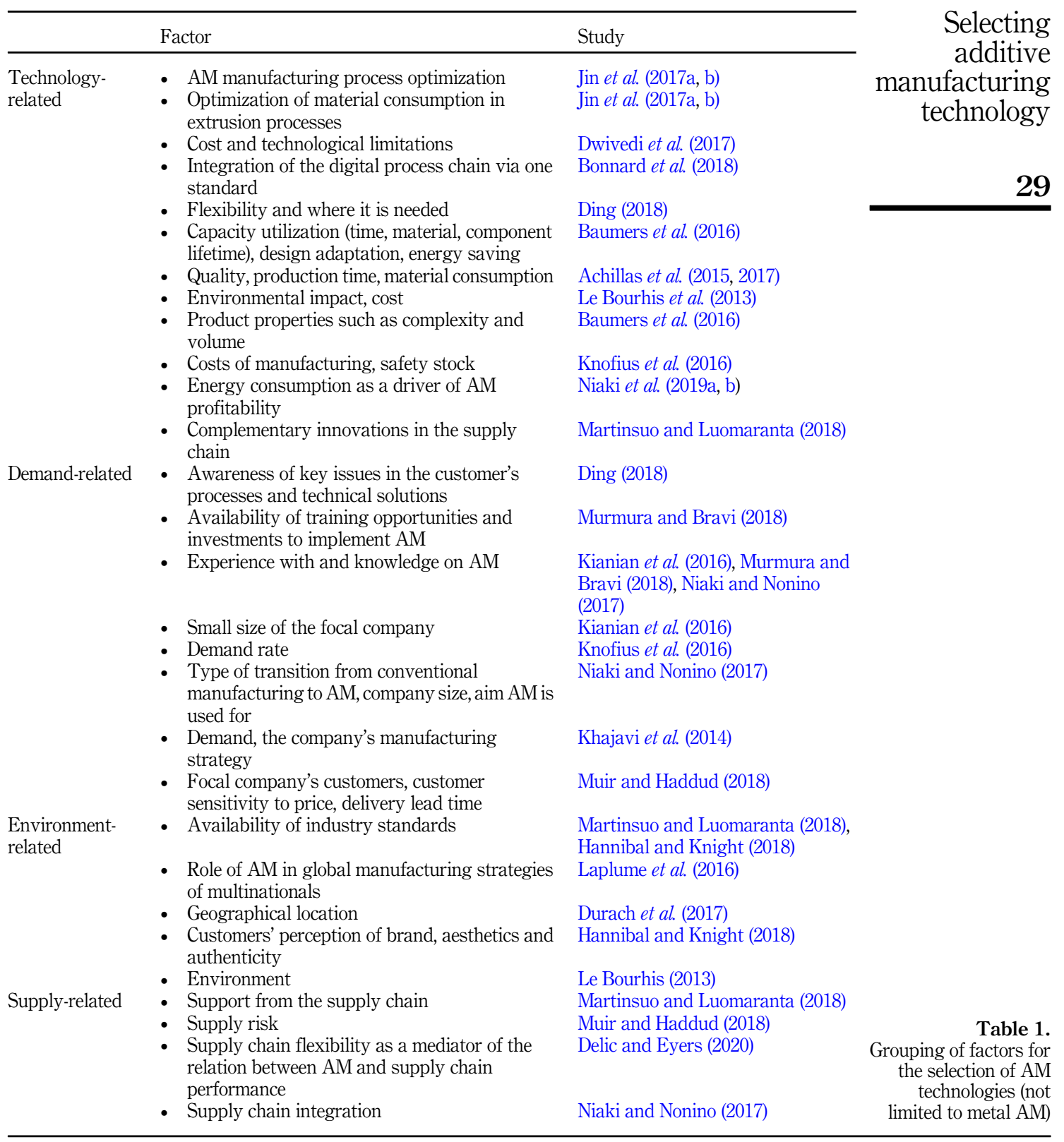

Literature study on factors for the selection of AM technology

In addition to the AM-specific literature in Table 1 and 2 , we also referred to seminal work on standard dominance (van de Kaa et al., 2011), technology diffusion (Ortt, 2010), business models (e.g. Demil and Lecocq, 2010; Joyce and Paquin, 2016) and technology acceptance 
JMTM

\begin{tabular}{lll}
\hline Source & $\begin{array}{l}\text { Method and derivation } \\
\text { of factors }\end{array}$ & Context \\
\hline $\begin{array}{l}\text { Schniederjans } \\
(2017)\end{array}$ & $\begin{array}{l}\text { Survey, statistical } \\
\text { analysis; diffusion of } \\
\text { innovation theory } \\
\text { (DOI), theory of } \\
\text { technology adoption } \\
\text { and usage }\end{array}$ & $\begin{array}{l}\text { 270 top- } \\
\text { management } \\
\text { representatives from }\end{array}$ \\
$\begin{array}{lll}\text { US manufacturing } \\
\text { firms }\end{array}$ \\
$\begin{array}{l}\text { Schniederjans } \\
\text { and Yalcin } \\
\text { (2018) }\end{array}$ & $\begin{array}{l}\text { Structured interviews, } \\
\text { nonparametric } \\
\text { statistical analysis } \\
\text { 16 factors from the five } \\
\text { most mainstream } \\
\text { innovation adoption } \\
\text { theories }\end{array}$ & $\begin{array}{l}\text { from US } \\
\text { manufacturing } \\
\text { firms }\end{array}$ \\
&
\end{tabular}

Yeh and Chen (2018)

Hasan et al. (2019)
Group decision analytic hierarchy process; nonsystematic AM literature review fitted into technologyorganizationalenvironment-cost framework

Delphi study; factors for mass adoption of $\mathrm{AM}$ in conventional manufacturing processes according to participants
18 upper

management level experts, Taiwanese manufacturing industry

Eight participants from the USA and UK, both from academia and industry
- Complexity, effort expectancy

- Perceived behavioral control

- Perceived ease of use

- Facilitating conditions

- Trialability

- Mimetic pressures, observability

- Government policy

- Top management support

- Organizational readiness

- Technology infrastructure

- Process automation

- Market demand

- Public acceptance

- Manufacturing speed
Table 2.

Overviews of empirical studies that prioritize factors for the selection of various $\mathrm{AM}$ technologies
Most important factors

- Relative advantage

- Compatibility

- Facilitating conditions

- Performance expectancy

- Performance expectancy

- Relative advantage

- Perceived usefulness

- Compatibility

- Social influence

- Coercive pressures

- Cost (material, machine, labor)

- Technology (relative advantage)

- Environment (partners)

- AM-adapted technical support and services

- Cost of products, production and post processing

- Machine tolerances, process stability, part-to-part variability

- Availability of quality assurance protocols

- Availability of materials, material property data and print parameters

- Increasing acceptance by large companies

(continued) 


\begin{tabular}{|c|c|c|c|c|c|}
\hline Source & $\begin{array}{l}\text { Method and derivation } \\
\text { of factors }\end{array}$ & Context & $\begin{array}{l}\text { Least important } \\
\text { factors }\end{array}$ & $\begin{array}{l}\text { Most important } \\
\text { factors }\end{array}$ & additive \\
\hline $\begin{array}{l}\text { Marak et al. } \\
\text { (2019) }\end{array}$ & $\begin{array}{l}\text { Survey, statistical } \\
\text { analysis, DOI theory }\end{array}$ & 92 Indian firms & $\begin{array}{l}\text { - Compatibility } \\
\text { - Observability }\end{array}$ & 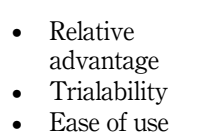 & $\begin{array}{r}\text { manulacturing } \\
\text { technology }\end{array}$ \\
\hline $\begin{array}{l}\text { Niaki et al. } \\
(2019 a, b)\end{array}$ & $\begin{array}{l}\text { BWM analysis, factors } \\
\text { collected in qualitative } \\
\text { survey }\end{array}$ & $\begin{array}{l}88 \text { companies across } \\
22 \text { countries } \\
\text { (survey), } 12 \mathrm{AM} \\
\text { experts (BWM) }\end{array}$ & 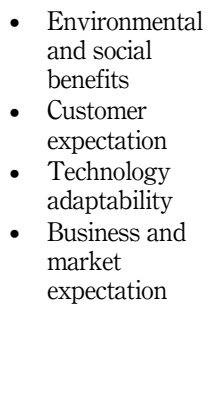 & $\begin{array}{l}\text { - AM enabling } \\
\text { creativity and } \\
\text { innovation } \\
\text { - } \text { Design } \\
\text { complexity and } \\
\text { customization } \\
\text { - Low-volume } \\
\text { production } \\
\text { - Quick and } \\
\text { economic } \\
\text { prototyping } \\
\text { - Cost and time } \\
\text { savings }\end{array}$ & 31 \\
\hline
\end{tabular}

(Davis, 1989). To obtain a complete set of factors for the selection of AM technologies, a literature search on ISI Web of Science was conducted using keywords related to acceptance, adoption, diffusion, innovation (with an asterisk, e.g. accept*) in combination with AM or synonyms thereof. After removing purely technical or conceptual articles, this led to the inclusion of 47 articles in the final study.

The literature study produced a list of 168 factors across 11 categories, though with much overlap and partly excessive level of detail. Hence, we removed duplicates, condensed excessively detailed factors into overarching concepts and deleted barriers that were also formulated as factors. For example, the factor capital requirement was deleted, as it is very similar to relative price/cost/effort. The level of detail was reduced by combining quality, material consumption, production time and user friendliness into relative technological performance. The barrier unavailability of skilled operators was deleted, as it is also captured in the factor sufficient education and skills development. We concluded with 39 factors grouped across several stakeholders, the innovation itself and the environment in which the innovation is selected, following the structure in Table 1.

We distinguish between demand-side innovator and supply-side innovator. Demand-side innovator refers to the customer as it "demands" innovations in the market. The customer could demand either AM machines or products and services based on AM. We refer to it as innovator to acknowledge that the introduction of a new technology represents an innovative activity for the developer of the technology as well as for the first-time user. In our situation, the demand-side innovator is the manufacturing company that adopts and implements AM technologies into its production process and develops new products and services based on it. Supply-side innovator refers to the actor that introduces an innovation in the market. In our situation, the supply-side innovator is the company that develops and produces AM machines to cater to the needs of the demand-side innovator. The innovation itself refers to the innovation that is introduced in the market by the supply-side innovator and that is adopted by the demand-side innovator. In our situation, the innovation is the AM machine or technology. We assume that the demand-side innovator has an innovation support strategy that describes efforts to implement the innovation into its existing production lines successfully. Other stakeholders refer to all other actors that influence this process, such as regulators and standardization organizations. All these activities take place against the 
JMTM 32,9

background of environmental-level factors, such as the degree of market uncertainty. The category business model comprises factors that describe properties of business models in AM across different actors. Table 3 presents detailed descriptions of the factors.

\section{Methodology}

Best-worst method

AM technology selection represents a multicriteria decision-making problem. The methodology used to analyze the relevant factors and determine their corresponding weight is the BWM (Rezaei, 2015, 2016). The BWM stands out with a relatively few comparisons compared to other methods such as analytic hierarchy process (AHP), while still delivering highly reliable weighs (Rezaei, 2015).

An MCDM problem usually takes the following form:

$$
A=\begin{gathered}
c_{1} \\
a_{1} \\
a_{2} \\
\vdots \\
a_{m}
\end{gathered}\left[\begin{array}{cccc}
p_{11} & p_{12} & \cdots & p_{1 n} \\
p_{21} & p_{22} & \cdots & p_{2 n} \\
\vdots & \vdots & \ddots & \vdots \\
p_{m 1} & p_{m 2} & \cdots & p_{m n}
\end{array}\right]
$$

where $\left\{c_{1}, c_{2}, \ldots, c_{n}\right\}$ is a set of criteria, $\left\{a_{1}, a_{2}, \ldots, a_{m}\right\}$ is a set of possible alternatives and $\left\{p_{i j}\right\}$ is the score of alternative $i$ on criterion $j$. For the choice of a most promising alternative, an alternative with the highest overall value needs to be determined. Therefore, weights are attached to the criteria, denoted as $\left\{w_{1}, w_{2}, \ldots, w_{n}\right\}$, for which $w_{j} \geq 0$ and $\sum w_{j}=1$. The following term establishes the value of alternative $i$, denoted as $V i$ :

$$
V_{i}=\sum_{j=1}^{n} w_{j} p_{i j}
$$

The BWM is based on pairwise comparison to derive the factor weights. As its name suggests, the decision-maker needs to identify the best and the worst among the criteria, which will be compared to the remaining criteria in the next step. To determine the weights of the criteria, a maximin problem is formulated and solved. A consistency ratio indicates the reliability of the decision-maker's choices in the BWM.

The linear BWM can be completed in five steps (Rezaei, 2015, 2016):

(1) A set of decision-making criteria (factors) $\left\{c_{1}, c_{2}, \ldots, c_{n}\right\}$ needs to be determined (see Table 3).

(2) The best (e.g. most desirable or important) and the worst (e.g. least desirable or important) factors need to be identified.

(3) The preference of the best criterion over all other criteria needs to be indicated using numbers from 1 to 9 , where 1 indicates equal importance and 9 indicates most different importance. This results in the best-to-others vector:

$$
A_{B}=\left(a_{B 1}, a_{B 2}, \ldots, a_{B n},\right)
$$

$a_{B i}$ indicates the preference of the best criterion $B$ over criterion $j$.

(4) The preference of all criteria with respect to the worst criterion needs to be determined using numbers from 1 to 9 . Again, 1 indicates equal importance and 9 indicates most different importance. This results in the other-to-worst vector: 
Innovator characteristics (demand-side)

Customer level of education

Customer resources

Market demand

Customer installed base (previous, current, potential)

Intended frequency of use
Ability of the customer to utilize the innovation (Dedehayir et al., 2017)

Current financial condition of the customer who demands AM machines or products and services based on AM (Willard and Cooper, 1985)

Customers' current and forecasted demand (Dedehayir et al., 2017)

Number of units in which the innovation was in use (previous), is in use (current) or will potentially be in use (potential) (Greenstein, 1993)

Rate at which the product is planned to be used (Steenhuis and Pretorius, 2016)

Innovation characteristics (innovation itself)

Relative technological performance

Comparison of the product's characteristics to other alternative's characteristics (Schumpeter, 1934), for example, in terms of reliability, defect rate or ease of use (Baumers, Tuck, et al., 2016)

Compatibility

Flexibility

Perceived risk

Relative price/cost/effort

Complementary goods and services

Refers to whether two interrelated entities are compatible, whether older generations of a product are compatible with newer ones, also in terms of capabilities and radicalness of innovation (de Vries, 1999) Incremental costs of adapting the innovation to new customer needs, developments, etc. (van de Kaa et al., 2011)

Perceived likelihood that something will fail, and the perceived seriousness of the consequences if it does fail (Garbarino and Strahilevitz, 2004)

Cost of acquiring the innovation, including capital requirement, cost of taking it into use and training cost (Baumers, Dickens, et al., 2016) Availability of goods and services that are consumed together with the innovation (e.g. metal powders) (Teece, 1986)

\section{Innovator characteristics (supply-side)} Financial strength

Brand reputation and credibility

Operational supremacy

Learning orientation

Efficiency of production process

Enabling infrastructure, technology or production method

Financial means that are at the disposal of organization to support the innovation, both current and prospective financial means (Willard and Cooper, 1985)

Trust in the brand, benefits for society and potential threats (Corkindale and Belder, 2009)

Innovator's effectiveness in exploiting its resources relative to the effectiveness of the competitors (Schilling, 2002)

Innovator's capacity to acquire skills and absorb information but also to increase its absorptive capacity (Agarwal et al., 2004)

Characteristics of the production process, e.g. in terms of necessary ancillary process steps, build time or energy consumption (Baumers, Tuck, et al., 2016)

Necessary infrastructure for the innovation to unfurl its utility, e.g. high-power grid for charging stations for electric cars (Ortt, 2017)

Innovation support strategy

Pricing strategy, price structure

Appropriability strategy (IPR)

"All actions taken to create market share through strategically pricing the products in which the format has been implemented" (van de Kaa et al., 2011, p. 1404)

Efforts to protect the innovation against imitation by competitors (Lee et al., 1995)

Timing of entry

Strategic choice of a first market introduction of the innovation (van de Kaa et al., 2011)

(continued)

\section{Selecting additive manufacturing technology}


JMTM 32,9

34
Innovation support strategy

Marketing communications

Distribution strategy

Commitment (supply-side innovator)

Network formation and coordination strategy

Other stakeholders

Big Fish

Regulator

Standardization organization

Judiciary

Insurance company

Environmental-level factors

Bandwagon effect

Market uncertainty

Switching costs

Availability of rules and standards

Job opportunities

Sufficient education and skills development

Dissemination of AM in society

\section{Business model}

Imitability, scalability and integrability

Failure to identify actor or stakeholders

Failure to consider influencing factors
Communication with customers to manage expectations, e.g. by using strategic preannouncements, including sense of mission, lobbying activities or communicability (Shapiro and Varian, 1998) Usage of the distribution system for strategic purposes (Willard and Cooper, 1985)

Attention an innovation gets from the actors involved, in terms of support, usually in times of low returns on investment (Willard and Cooper, 1985)

Future direction and plan of action for forming and coordinating a network (Ortt, 2010)

Actors who can exert influence on the market through their buying power (Suarez and Utterback, 1995)

Public sector officials who specify regulations for a geographic area, for example, pertaining to liability (Suarez and Utterback, 1995)

Public sector agencies or networks that develop and publish standards, such as IEEE or ISO (Wu et al., 2018)

Legal system that interprets and applies laws as a means to solve conflicts (van de Kaa et al., 2011)

Companies that spread risk among insurance policyholders (Rothman, 1980)

Users choosing the same solution that others already have chosen for a similar problem (de Vries, 1999)

Customers hesitant to adopt when level of uncertainty is too high, e.g. rate of change, number of options available or unforeseen (micro) events including international political conflicts (van de Kaa et al., 2011)

Cost of switching between competing technologies or innovations, including resistance to change (Suarez, 2004)

Rules and standards available to promote the use of a technology (Ortt, 2010)

Perceived attractiveness of an industry as seen by job seekers, relative to other industries (Joyce and Paquin, 2016)

Opportunities to upgrade the skills of workers according to needs of the AM industry (Kianian et al., 2015)

Communication about AM as a production method in society. Higher dissemination increases familiarity with the technology (Steenhuis and Pretorius, 2016)

Extent to which the innovation/business model can be imitated, whether there is a significant cost and disadvantage for another organization to duplicate the innovation/business model, whether it can respond to increases in demand and whether it can be integrated with the whole value chain (Demil and Lecocq, 2010)

Inability to identify all actors and stakeholders in the business ecosystem (Joyce and Paquin, 2016)

Lack of awareness of trends such as potential technology

substitution and inability to adjust the business model accordingly (Chesbrough, 2010)

Table 3. 


$$
A_{W}=\left(a_{1 W}, a_{2 W}, \ldots, a_{n W},\right)
$$

$a_{j W}$ indicates the preference of the criterion $j$ over the worst criterion $W$.

(5) Lastly, the optimal weights $\left(w^{*} 1, w^{*} 2, \ldots, w^{*}{ }_{n}\right)$ need to be derived. This can be done by minimizing the maximum absolute differences, considering that weights must not be negative and that the sum of all weights must be equal to 1 . This results in the following minimax model:

$$
\begin{gathered}
\operatorname{minimax}_{j}=\left\{\left|\frac{w_{B}}{w_{J}}-a_{B j}\right|,\left|\frac{w_{j}}{w_{W}}-a_{j W}\right|\right\} \\
\text { s.t. } \\
\sum_{j} w_{j}=1 \\
w_{j} \geq 0, \text { for all } j
\end{gathered}
$$

The minimax model is then transformed:

$$
\begin{gathered}
\operatorname{Min} \xi \\
\text { s.t. } \\
\left|\frac{w_{B}}{w_{J}}-a_{B j}\right| \leq \xi, \text { for all } j \\
\left|\frac{w_{J}}{w_{W}}-a_{j W}\right| \leq \xi, \text { for all } j \\
\sum_{j} w_{j}=1 \\
w_{j} \geq 0, \text { for all } j
\end{gathered}
$$

The optimal weights and the reliability of the weights $\xi^{*}$ (consistency of the comparisons) are obtained by solving this equation. The closer $\xi^{*}$ is to zero, the higher the consistency and thus the reliability of the comparisons. The highest-scoring alternative can be selected by comparing the alternatives with respect to their overall values as determined in equation (2), while higher values are more desirable.

\section{Data collection}

The questionnaires were distributed to AM experts from various European countries. To qualify as experts, we required comprehensive knowledge of AM. Our sample of nine experts can be seen as a transdisciplinary team along the innovation value chain from both academia and the industry, all of whom are involved in studying and creating AM technologies. The data was collected in May 2019. Table 4 gives an overview of their backgrounds.

The first step of the BWM is to determine a set of decision criteria (factors) divided into categories (see Table 3). To compare the factors, we used a two-tiered approach: the steps described earlier were followed to determine the factor weights (by comparing factors within categories) and category weights (by comparing the categories). Multiplying factor weights and category weights leads to global weights. 


\begin{tabular}{|c|c|c|c|c|}
\hline $\begin{array}{l}\text { JMTM } \\
32,9\end{array}$ & Expert & Background & $\begin{array}{l}\text { Expertise (except for AM } \\
\text { technologies) }\end{array}$ & Function and organization \\
\hline & $\begin{array}{l}1 \\
2 \\
3\end{array}$ & $\begin{array}{l}\text { Industry } \\
\text { Academia } \\
\text { Academia }\end{array}$ & $\begin{array}{l}\text { 3D reconstruction engineer } \\
\text { Material science } \\
\text { Academic entrepreneurship }\end{array}$ & $\begin{array}{l}\text { Engineer, private company } \\
\text { Researcher, university } \\
\text { Lecturer/assistant professor, } \\
\text { university }\end{array}$ \\
\hline 36 & 4 & Academia & Industrial management & Researcher, university \\
\hline & $\begin{array}{l}5 \\
6\end{array}$ & $\begin{array}{l}\text { Industry } \\
\text { Academia }\end{array}$ & $\begin{array}{l}\text { Management } \\
\text { Innovation management and } \\
\text { entrepreneurship }\end{array}$ & $\begin{array}{l}\text { Manager, private company } \\
\text { Associate professor, university }\end{array}$ \\
\hline & 7 & Industry & Material science & Engineer/manager, private company \\
\hline & 8 & Industry, & Material science & Professor, university, private \\
\hline $\begin{array}{l}\text { Overview of } \\
\text { interviewed experts }\end{array}$ & 9 & Academia & Technology foresight & $\begin{array}{l}\text { Researcher, research and technology } \\
\text { organization }\end{array}$ \\
\hline
\end{tabular}

To ensure the reliability of the study, the participants were given definitions of the factors. Instructions and the opportunity to ask questions were offered during a webinar. After completion, the participants were asked to rank the importance of the factors based on intuition and gut feeling and to elaborate their choice in a few sentences. Some of the experts were interviewed for further elaboration of their decision and asked to reflect on the results of the study.

\section{Results}

Relative factor weights

Table 5 shows that the most important factors in the context are market demand (0.064), relative technological performance (0.064), imitability, scalability, integrability (0.064), failure to identify actors/stakeholders (0.061) and commitment (0.049).

Table 6 presents the consistency ratios for the comparison presented in Table 5. Out of the 72 comparisons, only three show a $\xi^{*}$ of larger than 0.2 (highest $\xi^{*}: 0,3922$ ), while 43 comparisons have a $\xi^{*}$ of below 0.1 - concluding that the comparisons are consistent (Rezaei, 2015).

\section{Robustness of the results}

The BWM itself cannot consolidate the resulting weights of different decision-makers so that results are typically aggregated by calculating average weights (Mohammadi and Rezaei, 2020). We test for the potential influence of outliers on the top five most important factors by excluding individual experts from the sample one at the time, an approach known as "leaveone-out" and common in economics (e.g. Caballero et al., 2004). After calculating the average global weights, we compared the top five most important factors with respect to the inclusion of the same factors in the top five. This test showed that that the top five most important factors are identical in five of the nine reduced samples (though with different rankings). In the other four cases, only one factor was different, and this difference did not correlate with the background of the experts (industry vs academia) showing that the addition of further experts to our sample would not likely alter the results significantly.

\section{Interpretation of factor weights}

Market demand, the highest-ranking factor of this study, refers to current and forecasted market demand. Currently, AM technologies cater to the demands of various small market 


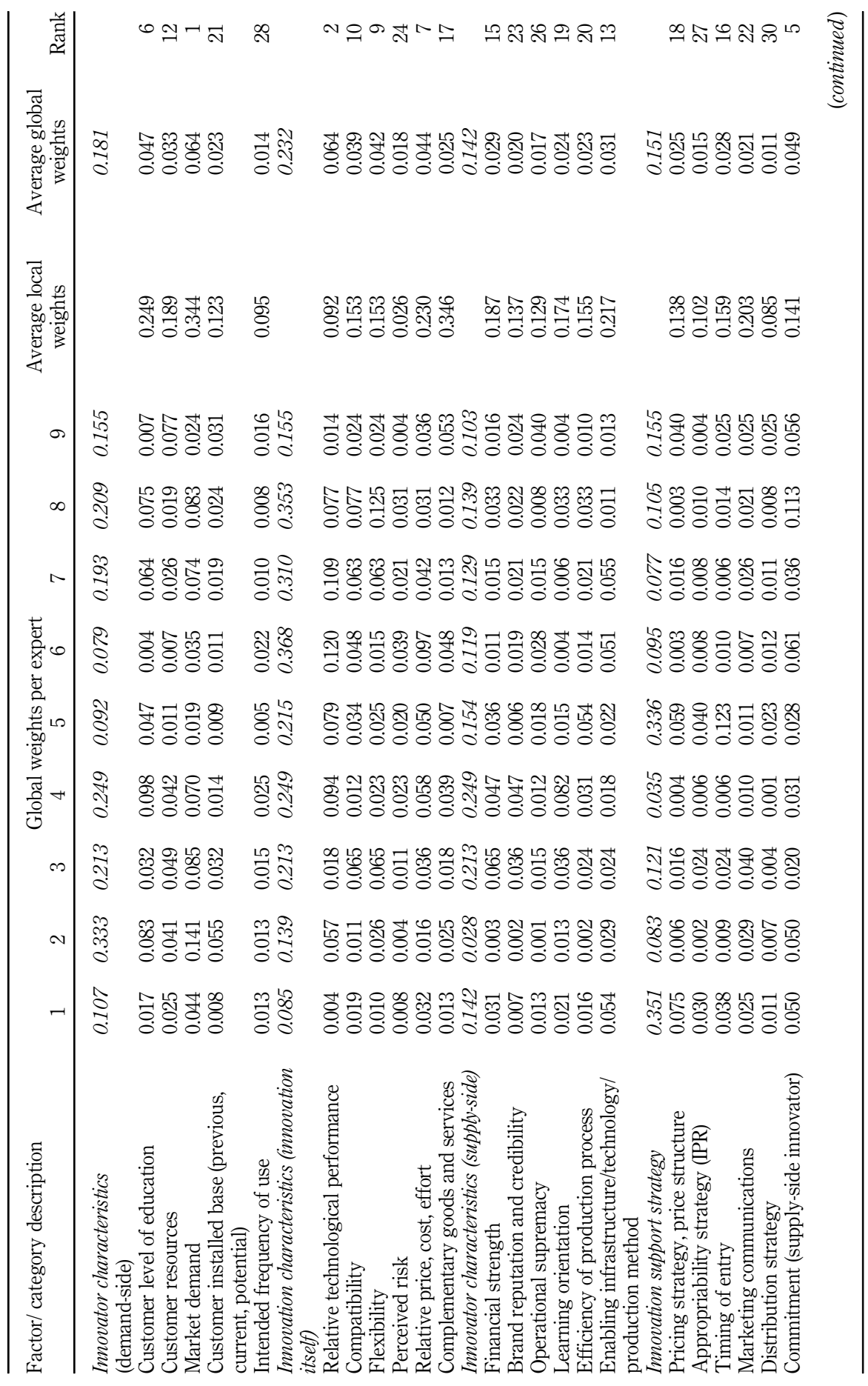




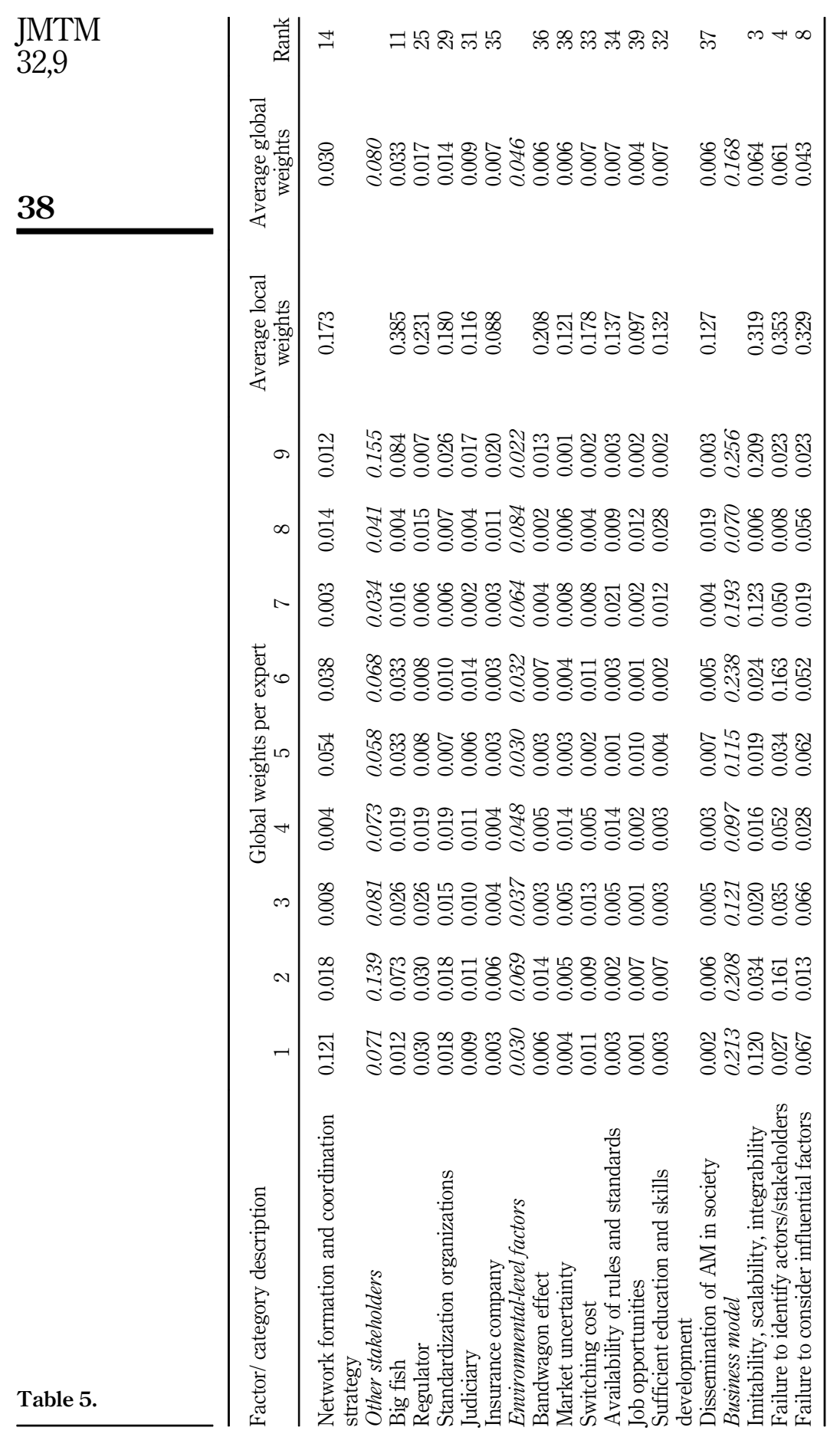




\begin{tabular}{|c|c|c|c|c|c|c|c|c|c|c|}
\hline Consistency ratio & 1 & 2 & 3 & 4 & $\begin{array}{c}\text { Expert } \\
5\end{array}$ & 6 & 7 & 8 & 9 & $\begin{array}{l}\text { Selecting } \\
\text { additive }\end{array}$ \\
\hline$\xi^{*}$ categories & 0.076 & 0.083 & 0.029 & 0.042 & 0.124 & 0.108 & 0.076 & 0.066 & 0.054 & $\operatorname{man}$ \\
\hline $\begin{array}{l}\xi^{*} \text { Innovator characteristics } \\
\text { (demand-side) }\end{array}$ & 0.057 & 0.071 & 0.055 & 0.112 & 0.103 & 0.126 & 0.072 & 0.104 & 0.109 & \\
\hline $\begin{array}{l}\xi^{*} \text { Innovation characteristics } \\
\text { (innovation itself) }\end{array}$ & 0.081 & 0.151 & 0.039 & 0.087 & 0.104 & 0.201 & 0.053 & 0.083 & 0.114 & \\
\hline $\begin{array}{l}\xi^{*} \text { Innovator characteristics } \\
\text { (supply-side) }\end{array}$ & 0.063 & 0.137 & 0.034 & 0.047 & 0.118 & 0.117 & 0.090 & 0.392 & 0.082 & \\
\hline$\xi^{*}$ Innovation support strategy & 0.085 & 0.086 & 0.065 & 0.066 & 0.111 & 0.127 & 0.077 & 0.080 & 0.057 & \\
\hline$\xi^{*}$ Other stakeholders & 0.077 & 0.131 & 0.044 & 0.029 & 0.135 & 0.121 & 0.088 & 0.150 & 0.118 & Table 6. \\
\hline$\xi^{*}$ Environmental-level factors & 0.066 & 0.154 & 0.077 & 0.044 & 0.100 & 0.097 & 0.060 & 0.111 & 0.092 & Consisten \\
\hline$\xi^{*}$ Business model & 0.063 & 0.211 & 0.042 & 0.042 & 0.042 & 0.183 & 0.140 & 0.133 & 0.000 & comparisol \\
\hline
\end{tabular}

niches, and AM companies have to engage in customer education to stimulate demand (Martinsuo and Luomaranta, 2018). It would certainly be easier for AM companies if there was a better understanding of the technology in the market and if they could cater to a strong demand. After the data collection and when the results were known, discussions with expert 4 highlighted the dichotomy with respect to demand for AM: how can customer demand be currently lacking and yet be the most important factor? AM is successfully catering to the needs of various niches, but on the other hand, the demand for AM is not high enough to enable the transition to large-scale production, which is still limited to few companies and applications (Ortt, 2017).

It is important to understand the situation that demand is the most important factor, yet demand is still limited. For major innovations, this is more often the case. At first there is most often only a small segment of users that knows the innovation, can value its benefits, can work with its initial limitations because the technology is not yet fully mature, and has a need that is intense enough to overcome all barriers that come with an emerging technology. One of those barriers that a major innovation may initially suffer from is the lack of standards or a dominant design. As a dominant design for AM technology has not yet been selected (Steenhuis and Pretorius, 2016), demand might be held back by different expectations in the market regarding the form and functionality of AM technologies. Tauber (1974) almost 50 years ago described that market research discourages major innovations because the small niche of users that need the innovation urgently is not large enough to emerge in a random sample exploring the market need for that innovation.

Relative technological performance compares the technological performance of the focal technology to other alternatives. As AM is struggling with part-to-part and machineto-machine variability (Martinsuo and Luomaranta, 2018), it is no surprise to find this factor among the highest-ranked. Contemporary metal parts production technologies, such as casting, are well developed and hence it is possible to produce parts with extremely low variability in specification. AM technologies are newer and perform very well in creating custom products, yet often suffer from higher variability in specification when used to produce larger numbers of parts. In practice, a relatively high proportion of AMmanufactured parts are condemned for further use. This factor was also mentioned to be the most important factor in the intuitive choice. Discussing the results, one respondent noted that relative technological performance leads to a unique selling point, competitiveness, higher value of products or to lower cost. Respondent 5 argues that is associated with higher earnings before interest and tax. Higher-performing AM technology may, for example, reduce the amount of necessary postprocessing of the parts and thereby increase profitability. 
JMTM 32,9

Regarding the business model factors (imitability, scalability, integrability and failure to identify actors/stakeholders), expert 2 noted that business models are the interface between products, markets and customers. The competitiveness of AM technology depends on the value it offers. As it often is more expensive than other manufacturing techniques, firms rely on AM to leverage some of its unique characteristics, rather than just replacing an existing process (Rayna and Striukova, 2016). Production of final parts with AM loosens the link between product and production site, as any AM machine that fulfills the manufacturing requirements may become a complementary asset (Rayna and Striukova, 2016) Taken together, new forms of value creation, products and service offerings are likely to be fed into new business models.

Commitment is the support actors give to an innovation. Currently, AM has a small market share in the overall manufacturing market, and many actors lack knowledge on AM and support from the supply chain (Martinsuo and Luomaranta, 2018; Murmura and Bravi, 2018). By supporting AM, for example, by engaging in customer education (ranked 6th), demand for AM could be increased, ultimately benefiting the selection of AM.

\section{Discussion}

The main factors and how they can be assessed in practice

The results suggest that the selection of metal AM technologies depends most on market demand and on their relative technological performance. Given that there are significant advantages attached to applying AM as a novel manufacturing technique, one would expect market demand for this technology to be high. In addition, as that factor is the most important for the selection of AM, one would expect AM to be the dominant metal manufacturing technology. However, counterintuitively, this is not the case and the question is why this is not the case.

First, in practice, assessing market demand and relative technological performance is not straightforward. AM is an emerging technology that is mainly applied in specific market niches instead of being a mainstream and dominant manufacturing technology (Ortt, 2017). A pattern of development and diffusion in which emerging technologies are first developed and applied in specific market niches, before a standard version of the technology emerges and is applied in mainstream markets, is well documented in theory (Geels, 2002; Tushman and Rosenkopf, 1992) and practice (Ortt, 2010). Examples of such market niches for AM are prototyping and local production of specific spare parts (Ortt, 2016). The consequences of AM application in different market niches are significant. The demands differ per niche and AM performance can be seen as fundamentally different per niche (although the focus of this study, metal AM, is already a niche within AM).

Alternative technologies of AM differ per market niche and hence the relative performance of AM compared to alternative technologies also differs per niche. Moreover, the performance requirements are significantly different in such early market niches in which AM is applied. Similarly, the factor relative technological performance is also well reflected in Martinsuo and Luomaranta's (2018) work as they find numerous challenges that fall under this factor, showing that the performance of AM technology is idiosyncratic to the specific context. The consequences of applying AM in subsequent market niches are also significant for other market factors of this study. The degree of imitability, scalability and integrability (ranked third) and the failure to identify actors and stakeholders (ranked fourth) may markedly differ for subsequent market niches.

Cost, compatibility and regulation may become increasingly important when AM grows to be a mainstream manufacturing technology. For market niches such as prototyping, however, AM is a cheap and fast technology compared to the old way of creating prototypes. A similar conclusion is possible for the use of AM in creating dental prostheses or specialized 
spare machine parts on location. In general, AM may be more expensive than contemporary manufacturing technologies, but for the niches in which AM is first applied, that is not the case.

\section{Comparison to studies with other results}

The importance of relative technological performance is in line with recent work by Martinsuo and Luomaranta (2018) and Schniederjans (2017), who find that technology-related adoption challenges are the third most mentioned and that relative technological advantage is a significant driver of managers' intention to adopt AM. Comparable conclusions are reached in the other studies in Table 2 (Hasan et al., 2019; Marak et al., 2019; Schniederjans and Yalcin, 2018; Yeh and Chen, 2018). The results provide evidence for Suarez's proposition (2004) that technological characteristics play an important role in the early phases of the technology selection process. Martinsuo and Luomaranta (2018) report that subcontractors are especially exposed to market demand as they cannot invest until they have orders.

Yeh and Chen (2018) find that cost and environment are the most important factors for the selection of AM in the Taiwanese manufacturing industry. Le Bourhis et al. (2013), Dwivedi et al. (2017), Martinsuo and Luomaranta (2018) and Niaki et al. (2019a, b) also consider cost to be an important factor and mention that if costs are too high, they could create a barrier. In our study, relative cost, price, effort are represented in the top ten, but with a significantly lower weight compared to the top three factors. This might be due to differences in the empirical context of studies related to geography and technology (e.g. metal AM vs AM in general). Yeh and Chen (2018) analyze AM as a whole rather than metal AM specifically. Le Bourhis et al. (2013) assess the environmental impact of AM, and Dwivedi et al. (2017) analyze barriers to adoption in the Indian automotive sector. Schniederjans and Yalcin (2018) find that compatibility is a high-ranking factor, contrasting the results of this study, as compatibility is ranked 10th with a weight of roughly half of the highest-ranking factor. This could be due to the differences in the definition of compatibility. Schniederjans and Yalcin (2018) define it as an "innovation's consistency with existing values, past experiences and needs" (p. 515), whereas the definition in this study is more focused on technical compatibility (see Table 3). Environmental factors such as availability of rules and standards or market uncertainty have similarly low weights as in other studies. In Yeh and Chen (2018) and Le Bourhis et al. (2013), factors related to competitiveness, market trends or policy had relatively low rankings, as were comparable factors in our study (e.g. regulator, standardization organization, big fish). Candi and Beltagui (2019) are an exception, suggesting that technological uncertainty moderates both innovation performance and business impact of AM. This means that high technological uncertainty likely amplifies advantages of AM such as no need for tooling or affordable customization that also relate to high-ranking factors such as relative technological performance (Khajavi et al., 2014).

The property of the BWM that the sum of the relative weights is equal to 1 has implications for the factor weights: the more factors in a BWM, the lower the average relative weight (see equation (7)). This is relevant when varying numbers of factors are compared per category, and it might explain to some extent why the factors in the category business model (only three factors compared to five to seven factors in the other categories) have high global weights. Nevertheless, this is only half of story as global weights are derived by multiplying category weights with local weights. Other BWM studies have not discussed the influence of a varying number of factors per subcategory. For example, in a study on the selection of bioethanol facility locations in Iran, three of the five highest-ranking factors stem from the smallest categories, ranging between two and five factors (Kheybari et al., 2019). In contrast, this is not the case in a study on standards for business-to-government data exchange (van de Kaa et al., 2018) or in the study on the selection of thermochemical conversion technology for biomass (van de Kaa et al., 2017).

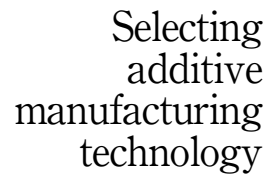


JMTM 32,9

\section{Conclusion}

This paper sought to answer the question "What are the most important factors for the selection of AM technology in the European context according to experts?" We conducted a literature study on relevant factors for AM technology selection, resulting in 39 factors. AMspecific literature together with seminal work on standard dominance, technology acceptance, business models and innovation diffusion was analyzed to develop a more robust framework. The 39 factors were prioritized in the context of metal AM by a group of European AM experts using the BWM method, followed by semistructured interviews. This revealed new, other than cost-related priorities and increased the understanding of the factor prioritization. The four highest-ranking factors are: (1) market demand, (2) relative technological performance, (3) imitability, scalability, integrability and (4) failure to identify actors/stakeholders.

\section{Theoretical contributions}

The set of 39 factors contributes toward a more holistic view of technology selection compared to existing frameworks and could serve as a starting point for future studies on the selection of metal AM technology specifically but also technology selection in general. The factor prioritization for metal AM showed that the broad literature study across literature streams was beneficial as none of the streams would have covered all factors on its own. The factors commitment and relative technological performance originate from the literature on standard dominance (van de Kaa et al., 2011), technology diffusion (Ortt, 2010), and AM adoption (e.g., Martinsuo and Luomaranta, 2018; Yeh and Chen, 2018), whereas the businessmodel-related factors were solely mentioned in the AM adoption respectively business model literature (Demil and Lecocq, 2010; Joyce and Paquin, 2016). Market demand was solely mentioned in the AM adoption literature. Although the individual domains are powerful on their own, this indicates that a broad literature study is worth the effort. Relatedly, the current study can be seen as a response to a call for more multiperspective research (Narayanan and Chen, 2012). The paper also offers explanations of why the factors are important based on literature and discussions with experts. In this respect, this study adds to a small but growing literature on prioritizing factors for AM adoption.

Further, this study also contributes to the MCDM and BWM methodology literature. The applicability of the BWM has already been confirmed in various studies that compared relatively few factors. Only one other study applied the BWM to an equally high number of factors. Malek and Desai (2019) derived relative weights for 39 barriers to sustainable manufacturing in Indian SMEs. The high consistency ratios of their study and the current study show that the BWM is well applicable to the comparison of more criteria based on a two-tiered system of category comparisons and criteria comparisons. Furthermore, we show how the "leave-one-out" approach that is common in economics can serve as a robustness measure for a ranking of factors in BWM studies.

\section{Practical contributions}

Firms face uncertainty when choosing between alternative manufacturing technologies. The framework of factors proposed in this paper may reduce this uncertainty. Although there are some case-specific aspects to this comprehensive framework, it may be applicable to technology selection in general with only minor adjustments. The prioritization of factors for metal AM provides a starting point for organizations with limited resources that cannot address all factors simultaneously. For firms who want to enter the AM market, the most important factors might provide guidance in understanding the industry.

The results highlight the importance of the business model component with respect to AM technology, reflecting the network nature of the problem. AM companies should actively 
engage in market and network development as there is no big market they can easily address. In situations such as the writing of a business plan, the proposed framework may serve as a starting point or inventory of areas to address. Furthermore, this study analyzes factors at a more abstract level as opposed to studies exploring few factors in more depth, highlights the complementary role of both study designs. More aggregate-level studies may help to place studies with a narrower scope in context, where the narrower-scoped studies add more detail by zooming in on specific factors.

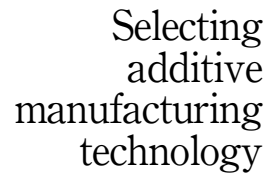

Limitations and future research

This study is based on expert opinions from a sample of nine European experts. Although the results of this study proved robust, future research could replicate the findings in other contexts and based on different experts. Further research could also study specific factors in depth and identify managerial strategies to address factors that were identified as most important. When studying factors for technology adoption, one faces the dilemma of level of detail versus clarity. Too many factors are difficult to compare meaningfully, whereas using very broad factors could reduce the utility.

We have already discussed that the evaluation of the factors may depend on the actual market niche. Similarly, future studies could assess the factors according to three categories of actors that in their own way adopt AM technologies or the result thereof. In a simplified value chain, Steenhuis et al. (2020) distinguish machine manufacturers that adopt the AM concept and produce AM machines, manufacturers adopting AM technology as part of their production process and customers who adopt products created by AM technology. These represent three categories of actors that almost inevitably use different criteria to decide about adoption of AM technology or AM products because of their position in the supply chain and because of their difference in knowledge. In some way, the case of AM technology shows that diffusion takes place by subsequent groups of actors in a chain.

Furthermore, future research could verify, based on hypothesis testing, whether the high-ranking factors of this study indeed correlate with or lead to the selection of AM technology. The current study focused on the selection of AM technology versus other manufacturing technologies. Future studies could focus on the selection of a dominant design for AM technology, as Steenhuis and Pretorius (2016) noted that a dominant design for AM technology has not yet been selected. Finally, future research could address how market factors such as market demand and relative technological performance (and the other high-ranking factors) not only differ in value but also in weight when they are assessed over time in different market niches.

\section{References}

3D Hubs (2019), “3D printing trends Q1 2019", available at: https://downloads.3dhubs.com/3D_ Printing_Trends_Q1_2019.pdf?utm_campaign $=$ Gated \%20Content $\% 20$ Downloads\&utm_ source $=$ hs_automation\&utm_medium $=$ email\&utm_content $=64642056 \& \_h s e n c=p 2 A N q t z-$ E6SdHiFni7dJn9wppEw5VbuzHVIHSw07t19gf5xGmyvWuvSeTmsfhsUzT64gjt_wmWUh61_ rgf9ziVFe7goGZ80QRgg\&_hsmi=64642056 (accessed 23 April 2019).

Achillas, C., Aidonis, D., Iakovou, E., Thymianidis, M. and Tzetzis, D. (2015), "A methodological framework for the inclusion of modern additive manufacturing into the production portfolio of a focused factory", Journal of Manufacturing Systems, Vol. 37, pp. 328-339.

Achillas, C., Tzetzis, D. and Raimondo, M.O. (2017), "Alternative production strategies based on the comparison of additive and traditional manufacturing technologies", International Journal of Production Research, Vol. 55 No. 12, pp. 3497-3509. 
JMTM 32,9

Agarwal, R., Echambadi, R., Franco, A.M. and Sarkar, M. (2004), "Knowledge transfer through inheritance: spin-out generation, development, and survival", Academy of Management Journal, Vol. 47 No. 4, pp. 501-522.

Atzeni, E. and Salmi, A. (2012), "Economics of additive manufacturing for end-useable metal parts", The International Journal of Advanced Manufacturing Technology, Vol. 62 Nos 9-12, pp. 1147-1155.

Baumers, M., Dickens, P., Tuck, C. and Hague, R. (2016a), "The cost of additive manufacturing: machine productivity, economies of scale and technology-push", Technological Forecasting and Social Change, Vol. 102, pp. 193-201.

Baumers, M., Tuck, C., Wildman, R., Ashcroft, I. and Hague, R. (2016b), "Shape complexity and process energy consumption in electron beam melting: a case of something for nothing in additive manufacturing?”, Journal of Industrial Ecology, Vol. 21 No. S1, pp. S157-S167.

Bonnard, R., Hascoët, J.-Y., Mognol, P. and Stroud, I. (2018), "STEP-NC digital thread for additive manufacturing: data model, implementation and validation", International Journal of Computer Integrated Manufacturing, Vol. 31 No. 11, pp. 1141-1160.

Caballero, R.J., Cowan, K.N., Engel, E.M. and Micco, A. (2004), Effective Labor Regulation and Microeconomic Flexibility, No. No. w10744, New Haven, Connecticut.

Candi, M. and Beltagui, A. (2019), "Effective use of 3D printing in the innovation process", Technovation, Vols 80-81, pp. 63-73.

Chesbrough, H. (2010), "Business model innovation: opportunities and barriers", Long Range Planning, Vol. 43 Nos 2-3, pp. 354-363.

Corkindale, D. and Belder, M. (2009), "Corporate brand reputation and the adoption of innovations", The Journal of Product and Brand Management, Vol. 18 No. 4, pp. 242-250.

Davis, F.D. (1989), "Perceived usefulness, perceived ease of use, and user acceptance of information technology", MIS Quarterly, Vol. 13 No. 3, p. 319.

de Vries, H.J. (1999), Standardization: A Business Approach to the Role of National Standardization Organizations, Springer Science and Business Media, Boston.

Dedehayir, O., Ortt, J.R., Riverola, C. and Miralles, F. (2017), "Innovators and the early adopters in the diffusion of innovations: a literature review", International Journal of Innovation Management, Vol. 21 No. 8, doi: 10.1142/S1363919617400102.

Delic, M. and Eyers, D.R. (2020), "The effect of additive manufacturing adoption on supply chain flexibility and performance: an empirical analysis from the automotive industry", International Journal of Production Economics, Vol. 228, p. 107689.

Demil, B. and Lecocq, X. (2010), "Business model evolution: in search of dynamic consistency", Long Range Planning, Vol. 43 Nos 2-3, pp. 227-246.

Ding, Y. (2018), "Process planning for laser wire-feed metal additive manufacturing system", The International Journal of Advanced Manufacturing Technology, Vol. 95, pp. 355-365.

Durach, C.F., Kurpjuweit, S. and Wagner, S.M. (2017), "The impact of additive manufacturing on supply chains", International Journal of Physical Distribution and Logistics Management, Vol. 47 No. 10 , pp. 954-971.

Dwivedi, G., Srivastava, S.K. and Srivastava, R.K. (2017), "Analysis of barriers to implement additive manufacturing technology in the Indian automotive sector", International Journal of Physical Distribution and Logistics Management, Vol. 47 No. 10, pp. 972-991.

Garbarino, E. and Strahilevitz, M. (2004), "Gender differences in the perceived risk of buying online and the effects of receiving a site recommendation", Journal of Business Research, Vol. 57 No. 7 , pp. 768-775.

Geels, F. (2002), "Technological transitions as evolutionary reconfiguration processes: a multi-level perspective and a case-study", Research Policy, Vol. 31 Nos 8-9, pp. 1257-1274. 
Gibson, I. (2017), "The changing face of additive manufacturing", Journal of Manufacturing Technology Management, Vol. 28 No. 1, pp. 10-17.

Greenstein, S.M. (1993), "Did installed base give an incumbent any (measureable) advantages in federal computer procurement?”, The RAND Journal of Economics, Vol. 24 No. 1, pp. 19-39.

Hannibal, M. and Knight, G. (2018), "Additive manufacturing and the global factory: disruptive technologies and the location of international business", International Business Review, Vol. 27 No. 6, pp. 1116-1127.

Hasan, S., Rennie, A., Hoque, M.R. and Ahmed, N. (2019), "Requirements for large-scale adoption of rapid manufacturing technologies", Cogent Business and Management, Vol. 6 No. 1, p. 1623151.

Holmström, J., Partanen, J., Tuomi, J. and Walter, M. (2010), "Rapid manufacturing in the spare parts supply chain: alternative approaches to capacity deployment”, Journal of Manufacturing Technology Management, Vol. 21 No. 6, pp. 687-697.

Jin, Y., Du, J. and He, Y. (2017a), “Optimization of process planning for reducing material consumption in additive manufacturing", Journal of Manufacturing Systems, Vol. 44, pp. 65-78.

Jin, Y., He, Y. and Du, J. (2017b), "A novel path planning methodology for extrusion-based additive manufacturing of thin-walled parts", International Journal of Computer Integrated Manufacturing, Vol. 30 No. 12, pp. 1301-1315.

Joyce, A. and Paquin, R.L. (2016), "The triple layered business model canvas: a tool to design more sustainable business models", Journal of Cleaner Production, Vol. 135, pp. 1474-1486.

Kellner, T. (2020), “'The next generation: this team of young engineers helped bring 3D printing inside the world's largest jet engine", GE reports, 26 January", available at: https:/www.ge.com/ reports/the-next-generation-this-team-of-young-engineers-helped-bring-3d-printing-inside-theworlds-largest-jet-engine/ (accessed 20 March 2020).

Khajavi, S.H., Partanen, J. and Holmström, J. (2014), "Additive manufacturing in the spare parts supply chain”, Computers in Industry, Vol. 65 No. 1, pp. 50-63.

Kheybari, S., Kazemi, M. and Rezaei, J. (2019), "Bioethanol facility location selection using best-worst method", Applied Energy, Vol. 242, pp. 612-623.

Kianian, B., Tavassoli, S. and Larsson, T.C. (2015), "The role of additive manufacturing technology in job creation: an exploratory case study of suppliers of additive manufacturing in Sweden", Procedia CIRP, Vol. 26, pp. 93-98.

Kianian, B., Tavassoli, S., Larsson, T.C. and Diegel, O. (2016), "The adoption of additive manufacturing technology in Sweden", Procedia CIRP, Vol. 40, pp. 7-12.

Knofius, N., van der Heijden, M.C. and Zijm, W.H.M. (2016), "Selecting parts for additive manufacturing in service logistics", Journal of Manufacturing Technology Management, Vol. 27 No. 7, pp. 915-931.

Laplume, A.O., Petersen, B. and Pearce, J.M. (2016), "Global value chains from a 3D printing perspective”, Journal of International Business Studies, Vol. 47 No. 5, pp. 595-609.

Le Bourhis, F., Kerbrat, O., Hascoet, J.-Y. and Mognol, P. (2013), "Sustainable manufacturing: evaluation and modeling of environmental impacts in additive manufacturing", The International Journal of Advanced Manufacturing Technology, Vol. 69 Nos 9-12, pp. 1927-1939.

Lee, J.-R., O'Neal, D.E., Pruett, M.W. and Thomas, H. (1995), "Planning for dominance: a strategic perspective on the emergence of a dominant design", R\&D Management, Vol. 25 No. 1, pp. 3-15.

Luomaranta, T. and Martinsuo, M. (2020), "Supply chain innovations for additive manufacturing", International Journal of Physical Distribution and Logistics Management, Emerald Publishing, Vol. 50 No. 1, pp. 54-79.

Malek, J. and Desai, T.N. (2019), "Prioritization of sustainable manufacturing barriers using best worst method", Journal of Cleaner Production, Vol. 226, pp. 589-600.

Marak, Z.R., Tiwari, A. and Tiwari, S. (2019), "Adoption of 3D printing technology: an innovation diffusion theory perspective", International Journal of Innovation, Vol. 7 No. 1, pp. 87-103.

Selecting additive manufacturing technology 
JMTM 32,9

Martinsuo, M. and Luomaranta, T. (2018), "Adopting additive manufacturing in SMEs: exploring the challenges and solutions", Journal of Manufacturing Technology Management, Vol. 29 No. 6, pp. 937-957.

Mellor, S., Hao, L. and Zhang, D. (2014), "Additive manufacturing: a framework for implementation”, International Journal of Production Economics, Vol. 149, pp. 194-201.

Mohammadi, M. and Rezaei, J. (2020), "Bayesian best-worst method: a probabilistic group decision making model”, Omega, Vol. 96, p. 102075. doi: 10.1016/j.omega.2019.06.001.

Muir, M. and Haddud, A. (2018), "Additive manufacturing in the mechanical engineering and medical industries spare parts supply chain", Journal of Manufacturing Technology Management, Vol. 29 No. 2, pp. 372-397.

Murmura, F. and Bravi, L. (2018), "Additive manufacturing in the wood-furniture sector: sustainability of the technology, benefits and limitations of adoption", Journal of Manufacturing Technology Management, Vol. 29 No. 2, pp. 350-371.

Narayanan, V.K. and Chen, T. (2012), "Research on technology standards: accomplishment and challenges”, Research Policy, Vol. 41 No. 8, pp. 1375-1406.

Niaki, M.K. and Nonino, F. (2017), "Impact of additive manufacturing on business competitiveness: a multiple case study", Journal of Manufacturing Technology Management, Vol. 28 No. 1, pp. 56-74.

Niaki, M.K., Nonino, F., Palombi, G. and Torabi, S.A. (2019a), "Economic sustainability of additive manufacturing: contextual factors driving its performance in rapid prototyping", Journal of Manufacturing Technology Management, Emerald Publishing, Vol. 30 No. 2, pp. 353-365.

Niaki, M.K., Torabi, S.A. and Nonino, F. (2019b), "Why manufacturers adopt additive manufacturing technologies: the role of sustainability", Journal of Cleaner Production, Vol. 222, pp. 381-392.

Ortt, J.R. (2010), “Understanding the pre-diffusion phases”, in Tidd, J. (Ed.), Gaining Momentum Managing the Diffusion of Innovations, Imperial College Press, London, pp. 47-80.

Ortt, J.R. (2016), "Guest editorial”, Journal of Manufacturing Technology Management, Vol. 27 No. 7, pp. 890-897.

Ortt, J.R. (2017), "Is additive manufacturing evolving into a mainstream manufacturing technology?", Journal of Manufacturing Technology Management, Vol. 28 No. 1, pp. 2-9.

Rayna, T. and Striukova, L. (2016), "From rapid prototyping to home fabrication: how 3D printing is changing business model innovation", Technological Forecasting and Social Change, Vol. 102, pp. 214-224.

Rezaei, J. (2015), "Best-worst multi-criteria decision-making method”, Omega, Vol. 53, Supplement C, pp. 49-57.

Rezaei, J. (2016), "Best-worst multi-criteria decision-making method: some properties and a linear model”, Omega, Vol. 64, Supplement C, pp. 126-130.

Rothman, R.P. (1980), "The definition of 'business of insurance' under the McCarran-Ferguson act after 'royal drug", Columbia Law Review, Vol. 80 No. 7, pp. 1475-1492.

Schilling, M. (2002), "Technology success and failure in winner-take-all markets: the impact of learning orientation, timing, and network externalities", The Academy of Management Review, Vol. 45 No. 2, pp. 387-398.

Schniederjans, D.G. and Yalcin, M.G. (2018), "Perception of 3D-printing: analysis of manufacturing use and adoption”, Rapid Prototyping Journal, Vol. 24 No. 3, pp. 510-520.

Schniederjans, D.G. (2017), "Adoption of 3D-printing technologies in manufacturing: a survey analysis", International Journal of Production Economics, Vol. 183, pp. 287-298.

Schumpeter, J.A. (1934), The Theory of Economic Development: An Inquiry into Profits, Capital, Credit, Interest, and the Business Cycle, Harvard University Press, Cambridge, MA, Original Work Published. 
Shapiro, C. and Varian, H.R. (1998), Information Rules: A Strategic Guide to the Network Economy, Harvard Business Press, Boston, Massachusetts.

Steenhuis, H.J. and Pretorius, L. (2016), "Consumer additive manufacturing or 3D printing adoption: an exploratory study", Journal of Manufacturing Technology Management, Vol. 27 No. 7, pp. $990-1012$.

Suarez, F.F. and Utterback, J. (1995), "Dominant designs and the survival of firms", Strategic Management Journal, Vol. 16 No. 6, pp. 415-430.

Suarez, F.F. (2004), "Battles for technological dominance: an integrative framework", Research Policy, Vol. 33 No. 2, pp. 271-286.

Tauber, E.M. (1974), "How market research discourages major innovation”, Business Horizons, Vol. 17 No. 3, pp. 22-26.

Teece, J. (1986), "Profiting from technological innovation: implications for integration, collaboration, licensing and public policy", Research Policy, Vol. 15 No. 6, pp. 285-305.

Tushman, M. and Rosenkopf, L. (1992), "Organizational determinants of technological change toward a sociology of technological evolution", Research in Organisational Behaviour, Vol. 14, pp. 311-347.

van de Kaa, G., van den Ende, J., de Vries, H.J. and van Heck, E. (2011), "Factors for winning interface format battles: a review and synthesis of the literature", Technological Forecasting and Social Change, Vol. 78 No. 8, pp. 1397-1411.

van de Kaa, G., Kamp, L. and Rezaei, J. (2017), "Selection of biomass thermochemical conversion technology in The Netherlands: a best worst method approach", Journal of Cleaner Production, Vol. 166, pp. 32-39.

van de Kaa, G., Janssen, M. and Rezaei, J. (2018), "Standards battles for business-to-government data exchange: identifying success factors for standard dominance using the best worst method", Technological Forecasting and Social Change, Vol. 137, pp. 182-189.

Weller, Kleer, R. and Piller, F.T. (2015), "Economic implications of 3D printing: market structure models in light of additive manufacturing revisited", International Journal of Production Economics, Vol. 164, pp. 43-56.

Willard, G.E. and Cooper, A.C. (1985), "Survivors of industry shake-outs: the case of the US color television set industry", Strategic Management Journal, Vol. 6 No. 4, pp. 299-318.

Wu, P., Zhao, X., Baller, J.H. and Wang, X. (2018), "Developing a conceptual framework to improve the implementation of 3D printing technology in the construction industry", Architectural Science Review, Vol. 61 No. 3, pp. 133-142.

Yeh, C.-C. and Chen, Y.-F. (2018), "Critical success factors for adoption of 3D printing”, Technological Forecasting and Social Change, Vol. 132, pp. 209-216.

Zhang, X.-Y., Fang, G. and Zhou, J. (2017), "Additively manufactured scaffolds for bone tissue engineering and the prediction of their mechanical behavior: a review", Materials, Vol. 10 No. 1, p. 50.

\section{Corresponding author}

Vladimir C.M. Sobota can be contacted at: v.c.m.sobota@tudelft.nl

For instructions on how to order reprints of this article, please visit our website:

www.emeraldgrouppublishing.com/licensing/reprints.htm

Or contact us for further details: permissions@emeraldinsight.com 